\title{
A systematic approach to the analysis of sustainable development of a coal mining region
}

\author{
Oksana Sheveleva*, Ekaterina Slesarenko, Nina Vagina, and Vladimir Mishchenko \\ T.F. Gorbachev Kuzbass State Technical University, Department of Finance and Credit, 650000, \\ Vesennya st., 28, Kemerovo, Russia
}

\begin{abstract}
A systematic approach to the analysis of sustainable development of a coal-mining region, substantiated in the light of the growing and intensifying problems of an ecological, technological, social nature, determined by the specifics of territorial functioning, which causes a high susceptibility of the regional economy to external challenges, the main of which is currently high volatility of coal export prices, is presented in the article. In the conditions of the existing excessive orientation of the development of coal-mining regions towards the influence of the economic factor based on the principle of extracting maximum benefits, which, among other things, have historical prerequisites, there is a need to revise the theoretical concepts of sustainable development of territories from the point of view of a systematic approach that substantiates interconnection of many more components of sustainable development of regional economies. Thus, it is advisable to present the analysis of sustainable development of a coal mining region through the interaction of five interdependent components: culture and education component, social well-being component, science and innovation component, environment component and economic efficiency component.
\end{abstract}

\section{Introduction}

The growing regional problems of an innovative, technological, social, economic nature, caused by the specifics of the functioning of the territories, which consists in the hypertrophied growth of the low-innovative coal mining sector in the context of the curtailment of the scale of economic activity of industries producing products with high added value, increases the existing environmental threats, as well as susceptibility of regional economy to the influence of external shocks and disturbances (the most obvious of which is currently a decrease in export prices for coal), which requires a rethinking of approaches to ensuring sustainable development of coal mining regions, allowing to expand the boundaries of the studied components, as well as the relationship between them.

The improvement of such territories was initially carried out "with a bias" towards the influence of the economic factor on the principle of obtaining the maximum benefit.

*Corresponding author: shob.fk@kuzstu.ru 
Therefore, it is quite natural that social, environmental, scientific and innovation, cultural and educational issues took a back seat. Unfortunately, such tendencies are still determining the "image" of the regions in which the priority spheres of activity are the extractive industries.

However, if we prioritize not only the economic factor, but the interconnection of environment, economic efficiency, social, science and innovation, culture and education components, this will ultimately help to achieve the best effect in improving the efficiency of using the existing potential for sustainable development of territorial entities with a dominant extractive sector. Taking into account environmental factors in the development of regional concepts of sustainable development will make it possible to remove a number of social and economic problems or to reduce their importance for commodity-dependent regions.

\section{Materials and Methods}

The methods of comparative analysis, grouping, analogies, which were implemented on the basis of data from the Federal Services for Supervision of Consumer Rights Protection and Human Welfare, as well as state statistics were used in the work.

According to statistics, the share of industries related to mining accounted for about $40 \%$ in the structure of the gross regional product of the Kemerovo region in 2019 . The increase in the growth rate of industrial production in the coal mining industry in 2019 was $6 \%$. In 2019, 119.2 thousand people were employed in the coal mining industry in Kuzbass, i.e. $10 \%$ of the total number of people employed in the regional economy. The region ranks second in the country in terms of coal production. Thus, the Kemerovo region can be recognized as a typical example of coal areas.

The dynamics and level of social development of Kuzbass, the presence of significant social problems reflect the lag of the region in comparison with similar average Russian assessment parameters, and negative trends characterize the deterioration of a number of indicators that directly affect the quality of life of the population. This is often due to the impact of environmental factors and the lack of systemic measures for the implementation of sustainable development of the territory.

First, coal mining enterprises, carrying out their activities, act as the main "suppliers" of emissions and discharges of harmful substances into the air and water bodies.

The Kemerovo region in various reports and ratings is constantly among the leading regions with the maximum share of air samples from urban areas with an excess of the MPC of harmful substances.

Pollution of air and water bodies in commodity-dependent regions as a result of various adverse effects on the human body contributes to an increase in natural and migration loss of population.

Second, a significant social problem caused by the harmful effects of emissions and discharges of harmful substances into the air and water bodies on the human body, is an increase in the level of morbidity and an increase in disability of the population of the regions where coal mining enterprises operate.

Third, the extractive industries are characterized by the presence of a significant number of jobs with unsatisfactory health conditions (which leads to an increase in occupational diseases and pathologies), as well as a high risk of injury. In 2019, the Kemerovo Region, along with a number of other regions of our country, was included in the number of territories that were assigned the maximum rank of the impact of working conditions on the health of the working population.

Fourth, the priority in supporting the sectors of the economy with the lag in cash infusions into the cultural and educational cluster to meet the higher (non-physiological) 
needs of people, lead to degradation of the population in small single-industry territorial entities, an increase in alcoholism, drug addiction and the often associated spread of HIV infection, as well as the deterioration of the crime situation.

Fifth, as a result of the activities of coal mining enterprises, land plots that are not suitable for further use are taken out of operation, voids appear in soil, soil is polluted by industrial waste, disposal of dumps, discharges of contaminated industrial wastewater, the quality of soils of the residential zone located near mining enterprises deteriorates.

Sixth, the innovative inertia of coal mining enterprises and technological lag, which prevents the technological renewal of mining enterprises, the timely development of industries that meet modern realities (including those capable of making a significant contribution to the formation of GRP and contributing to the regional and municipal budgets), and, as a result, sustainable development of commodity-dependent regions. In this regard, diversification of the region's industry seems to be extremely necessary providing for an increase in the share of products with a high share of added value in the structure of GRP production based on the formation of an advanced technological platform, and an increase in the innovative activity of economic entities in the region.

\section{Results and Discussion}

Despite the similar views of scientists on the subject of sustainable development of the economy as its ability to maintain the given rates of socio-economic growth and development in conditions of permanently acting endogenous and exogenous shocks, the main components, determinants of such development are significantly differentiated in the works of economists. Thus, Nassreddine Garoui, Ezzeddine Ben Mohamed [1], Ingrid Visseren-Hamakers [2], Zineb Moumen, Najiba El Amrani El Idrissi, Manuela Tvaronavičienè, Abderrahim Lahrach [3], when determining sustainable development, proceed from the need to ensure harmonious interaction and dynamic equilibrium between society and the environment based on the intensification of economic growth in conditions of the least negative impact on the ecosystem. Another group of scientists (Hasan Volkan Oral [4], Vincent, S., Mulkey [5], S., Dauliyeva G., Yeraliyeva A., Sadykhanova G., Bimendiyeva L., [6]) finds the importance of social components in the studied concept that are mediated by ensuring economic security and the social welfare growth.

Thus, two main imperatives are mainly found in the systems analysis of the of "sustainable development" concept: ensuring environmental safety, which is associated with the need to preserve biodiversity and reduce the impact of industry on the environment, as well as ensuring socio-economic security, which is determined by the need to improve social well-being, living standards of the population.

Such a presentation of the studied concept seems to be fair; however, in the modern conditions of the functioning of regional economic systems associated with permanent external challenges and shocks of an economic, environmental, and epidemiological nature, as well as the presence of regional problems and the specifics of spatial development, is insufficient, because it neglects the need to involve such components as science, innovation, technology, intelligence in the process of ensuring sustainable development, which greatly increase its potential. This gap in the scientific and methodological presentation of the studied concept is partially solved by a group of scientists, which reveals the relationship between science, education, innovation and sustainable development in their works (K. Mijanovic, Marko Jukić, Jefimija Mijanovic Jukic [7], Mani P., Ramakrishnan R. [8], Diana-Mihaela Țîrcă, Bruno Silvestre, M Isabel Novo-Corti, Rabontu Cecilia Irina [9], James Jude, Abubakar Kazeem [10]). In earlier publications, the authors, together with other scientists, also attempted to link the state of the environment of an industrial region with its scientific and technological capabilities and potential [11], 
determining the particular importance of innovations in the context of a deteriorating environmental situation in commodity-dependent regions.

However, the presented works do not define the concept under study from the point of view of a systematic approach that substantiates the interconnections of a much larger number of components of sustainable development of regional economies. Attempts made by individual researchers to present the complex nature of the relationship between various aspects of sustainable development - intellectual, innovation, educational, cultural, environmental and moral - have not yet become mainstream of the modern theory of sustainable development.

The authors find the main prerequisites for rethinking the content of the studied concept in the following trends, which have recently intensified their negative impact on providing of sustainable development of the Kemerovo region as a typical coal-mining region:

- increasing anthropogenic impact on the environment;

- the exhaustion of traditional resources, including those that ensure energy, food selfsufficiency and security;

- critical accumulation of industrial and household waste, the impossibility of their complete disposal;

- "aging" of fixed capital;

- a decrease in the quality of labor resources against the background of a reduction in high-productivity jobs and worsening working conditions;

- growth of excess production in the absence of effective demand;

- the imposition of a model of unethical consumption - a type of consumer behavior that neglects the growing social and environmental problems;

- decrease in the social well-being of the population;

- an increase in economic, technological, social and cultural divergence.

\section{Conclusion}

Based on the selected prerequisites, the content of the studied concept should consist of the following interrelated and interdependent components, which are imperatives of sustainable development:

1) taking into account environmental consequences when making organizational, managerial and implementation decisions related to anthropogenic impact on the ecosystem of the region;

2) intensification of industrial and production activities in conditions of rational use of non-renewable resources by increasing its intellectual intensity, development and implementation of advanced production technologies;

3) improving social well-being by creating conditions for increasing the scientific and inventive potential of society as the basis for creating a social class with high innovation and entrepreneurial activity;

4) formation of a model of consumer behavior focused on the principles of ethical, responsible consumption.

In order to implement these imperatives, the factors of sustainable development of the economy of a coal mining region are: inventive and entrepreneurial activity of society, science, innovation, institutional and structural reforms, highly qualified personnel. From this point of view, sustainable development is the development of the economy over a long period, achieved on the basis of intensive factors, not only quantitative, but also qualitative changes that have a cumulative nature in the context of the need to maintain a healthy environment and mitigate emerging external risks.

Thus, the basis for the sustainable development of a coal-mining region should be a consistent and systematic process of increasing the efficiency of the life of a territorial 
entity through a symbiosis of five components: environment, economic efficiency, social, science and innovation, culture and education. A significant emphasis on one of the parts, as a rule, introduces an imbalance in overall development, ultimately hampering the achievement of regional strategic goals.

In the context of the deterioration of the environmental situation in the commoditydependent regions, actually caused by the low contribution of environmental and technological innovations to production processes, the degradation of cultural values, the neglect of environmental and moral norms, the formation of consumptive and irresponsible behavior of business owners, the prospective development of a coal mining region should be determined by the increasing role of social, science and innovation, culture and education determinants that determine the stabilization and sustainable socio-economic situation in the region. Thus, a systematic approach to the sustainable development of the Kemerovo region - as a typical coal-mining region - is based on five interdependent components (social well-being component, culture and education component, environment component, science and innovation component, economic efficiency component).

The interrelation of the presented components is mediated by both direct and reverse influence, while exerting a positive impact on the sustainable development of a coal-mining region through ensuring environmental safety or preventing it. So, the activation of the scientific and innovation component through the creation of high-performance jobs, the formation of a system of continuous retraining and advanced training, increasing the importance and the dissemination of ideas of environmental thinking and education in society, the formation of the image of a "new person" as an innovatively active person, ready to take on social and environmental responsibility for her or his activities will lead to a progressive transformation of the sectoral structure through the diversification of industrial production, an increase in the share of high-tech and knowledge-intensive industries, as well as the formation of demand for the products of these industries. On the other hand, the intensification of innovative factors of production will launch the process of an overflow of labor resources from industries that use mainly low-skilled labor in industries that requires highly qualified personnel, ensuring the transformation of the social structure and, as a result, an increase in the social well-being of the population. Improving social well-being will determine sustainable trends towards increasing the economic efficiency of the exploited factors of production, creating a stable demand for innovative products and technologies, and at the same time, creating the potential for future, new conditions for the socio-economic, innovative and technological development of the regional economy.

\section{References}

1. N. Garoui Ezzeddine Ben Mohamed Agrociencia, 54(2) (2020)

2. I. Visseren-Hamakers, Earth Syst. Gov, 100047 (2020)

3. Z. Moumen, N. El Amrani El Idrissi, M. Tvaronavičienè, A. Lahrach, Insights into Reg. Deve,. 1 (4) (2019)

4. H. Volkan Oral, The Palgrave Encyclop. of Glob. Sec. Stud (2020)

5. S. Vincent, S. Mulkey, Environ, Develop. and Sustain, 17 (2015)

6. G. Dauliyeva, A. Yeraliyeva, G. Sadykhanova, L. Bimendiyeva, E3S Web of Conf, 159 (2020)

7. K. Mijanovic, M. Jukić, J. Mijanovic Jukic, IRASA Sec. Int. Sci. Conf (2020)

8. P. Mani, R. Ramakrishnan, Conf.: Emerging Strides in Innovations and Skill Enhancement - Sustainable Development a key focus (2018) 
9. D. Țîrcă, B. Silvestre, I. Novo-Corti, R. Cecilia Irina, J. of Cleaner Production, 133 (2016)

10. J. Jude, A. Kazeem, Int J. Sci Res Sci Technol, 6(1) (2019)

11. O. Sheveleva, E. Slesarenko., N. Kudrevatykh., T. Mamzina, E3S Web of Conf. The conference proceedings Sustainable Development of Eurasian Mining Regions: electronic edition, 134 (2019) 